\title{
A Proposed Framework Of Mediating Role Of Interpersonal Employee Conflict Between The Relationship Of Servant Leadership And Academicians OCB, Using PLS
}

\author{
Mehwish Rashid, Rosmaini Tasmin, Muhammad Imran Qureshi, Muhammad Shafiq
}

\begin{abstract}
Interpersonal employee conflicts exist in every organization, which relates to Organizational citizenship behaviours of employees. This study investigates the mediating role of interpersonal employee conflict between the relationship of servant leadership approach and academicians $O C B$. Variance based structure equation modeling is implementes as smar PLS is used to investigate the reltionship. A new framework is proposed as Interpersonal employee conflict mediates the relationship between servant leadership and academicians OCB. It is recommened to reduce the interpersonal employee conflict as these hampers the relationship between servant leadership dimensios ad academicians $\mathrm{OCB}$.
\end{abstract}

Keywords: Interpersonal Employee Conflict, Servant Leadership, Academicians OCB

\section{INTRODUCTION}

However, in any organization, effectiveness steps of leadership, could also be hampered by having conflicts among employees. In Malaysia, public academics are also faced with increased stress due to the rapid development in the higher education sector. Study done among Malaysia education officials revealed that lack of clear-cut policies and lack of good working procedures played a significant role in initiating stress (Okonkwo Mukosolu,1 Faisal Ibrahim,1 Lekhraj Rampal,1 Normala Ibrahim, 2015). Malaysian academics can be assessed through their teaching, supervision, publication, training, student service, administrative duties, and social responsibility. Teaching as a profession has been ranked as the second most stressful occupation (Johnson, 2005). Previous studies have shown that Malaysian academic staffs face high job stress due to development of Malaysian tertiary education sectors where interpersonal conflicts and role ambiguity occur (Zafir \& Hizam, 2013; Idris, 2009).

Though, the concept of OCB has been less researched at the university level (Dipaola \& Mendes da Costa Neves, 2009; Jurewicz, 2004). There have been numerous studies conducted OCB in Malaysian public schools (Emmerik

Revised Manuscript Received on April 19, 2019. and Business, Universti Tun Hussein Onn Malaysia, Johor Malaysia.

Rosmaini Tasmin, Associate Professor, Faculty of Technology Management and Business, Universiti Tun Hussein Onn Malaysia, Johor Malaysia.

Muhammad Imran Qureshi, Senior Lecturer, Faculty of technology Management and Technoprenurship, Universiti Teknikal Melaaca, Malaysia.

Muhammad Shafiq, Assistant Professor, Muhammad Ali Jinnah University, Karachi, Pakistan.
Mehwish Rashid, PhD scholar, Faculty of Technology Management

\&Euwema, 2007), but there is a lack of studies in universities, especially in MTUN universities, which leaves an interesting gap. There have not been prominent work on interpersonal conflicts as mediators, moreover there is a research gap on the impact of servant leadership approach on employee interpersonal conflicts, especially in MTUN universities. Servant Leadership (SL) as the independent variable, OCB as the dependent variable by incorporating Interpersonal Employee Conflict (IEC) as a mediating variable. This study used Partial Least Square (PLS) technique as a variance base SEM.

\section{INTERPERSONAL EMPLOYEE CONFLICT}

An interpersonal conflict can be defined as "An interaction between two person's dependent of each other who notice a contradiction in their goals, values, ideas or activities" de Reuver (2003). Nothing stimulates as many forms of interpersonal conflict as does the workplace, probably. It emerges from coworkers' personality difference, bullying behavior, rivalries or differences of opinions or difference in objectives of the employees. "Conflict in workgroups is a pervasive problem faced by organizations" (Thomas, Bliese \& Jex, 2005). The interpersonal conflict also called relationship conflict is "an awareness of interpersonal incompatibilities and disagreement about interpersonal issues among group members". It arises from bitterness, unease, and unfriendly behaviors (Jehn \& Mannix, 2001). According to Barki \& Hartwick (2004) interpersonal conflict as a dynamic process that occurs between interdependent individuals, groups, or both, as they experience negative emotional reactions. This study was used Barki \& Hartwick 9 items of Interpersonal Conflict Organizational Scale (ICOS).

\section{ORGANIZATION CITIZENSHIP BEHAVIOUR}

For any organization, the establishment of OCB is imperative. OCB is defined as employee behavior that exceeds the outlined job specifications that directly or indirectly facilitate the completion of organizational goals (Organ et al., 2005). OCB is defined as participating in activities or actions that are not formally a part of the job description, but that benefit the organization as a whole 
(Borman, 2004). OCB is often referred to as extra-role performance or contextual performance of employees Bambale (2014). From the literature it is observed that leadership is the key agent in promoting OCB, different leadership components have a relationship with OCB (Poohongthong et al., 2014). Trust of the leader for their followers and making them empower will improve OCB among them (Runhaar et al., 2013). Results of previous studies reveal that more engaged lecturers are found more helpful towards colleagues. Similarly, more engaged lecturers show positive reaction towards the organization. In both cases, OCB plays its role (Runhaar et al., 2013). In fact, OCB is identified as an emerging field of study in education that can be very helpful in improving the overall efficiency of the universities (Kernodle \& Noble, 2013).

\section{SERVANT LEADERSHIP}

Servant leadership offers a multidimensional leadership theory that encompasses all aspects of leadership, including ethical, relational, and outcome-based dimensions. Servant leadership has been found appropriate in the business, government and non-profit sectors, and equally important and appropriate in the educational sector (Barbuto \& Wheeler, 2006). Barbutto \& Wheeler (2006) five construct interpretation has been chosen in the theoretical framework as the independent variable of the present study. The fiveconstruct of SL was Altruistic calling, Emotional healing, Wisdom, Persuasive mapping, and Organizational stewardship was chosen to measure servant leadership. This study was used 23 items of Servant Leadership Questionnaire of Barbutto \& Wheeler (2006).

\section{MEDIATING ROLE OF INTERPERSONAL EMPLOYEE CONFLICT BETWEEN SERVANT LEADERSHIP AND OCB}

From the social exchange theory (Blau, 1964), "interpersonal conflict represents a prevalent challenge in organizations as it can create an imbalance in the employeeemployer relationship. Researchers have focused on the individual outcomes of interpersonal conflict such as intensified internal conflicts, anxiety, higher tension related to the job, lower job satisfaction and job involvement, less confidence in leaders and in the organization, propensity to leave an organization, absenteeism, work-family conflict, and lower commitment to the organization (Tubre \& Collins, 2000). Hence, the conflict is not only a micro-level personal matter, but also an interpersonal issue leading to macro-level organizational consequences, such as low performance, depression, and higher turnover" (Jehn \& Mannix, 2001).

The current study used the social exchange theory to explain the relationship of interpersonal conflicts and OCB. Employees experience interpersonal demands like abrasive personalities and learning to work with a diverse group of people, experience higher levels of workload and stress (Morris, Messal \& Meriac, 2013). These higher levels of workload and stress most probably lead to interpersonal conflicts. Taking into account the more of leader social support employees perceive it could be proposed that employees experience less negative individual outcomes
(Glavin \& Schieman, 2010). Without the reduction in interpersonal anxiety which social support should accomplish employees can most probably not participate in strong and high-quality developmental relationships as described by (Rock \& Garavan, 2011). When employees experience conflict from someone their motivation to participate in OCB activities are decrease. When employees experience a disruption in their learning network due to stress or a hostile environment this influences their less intention to participate in OCB. As mentioned before, interpersonal conflicts were associated with a range of negative individual outcomes (Glavin \& Schieman, 2010).

There are many studies in which the mediating effect of interpersonal employee conflict was investigated with other leadership approaches and organizational outcomes. The mediating effects of organizational conflict on the relationships between workplace ostracism with in-role behavior and OCB have been reported (Chung, 2015). The result of this study found that coworker conflict was found to mediate the relationships between workplace ostracism with in-role behavior and OCBs. Although a handful of studies have shown servant leaders relationships to OCBs to be mediated by mechanisms such as promotion focus (Neubert et al., 2008) and procedural justice climate (Ehrhart, 2004). Zehir et al. (2013) also found that employees' perceptions of organizational justice mediated the relationship between servant leadership and both OCB and job performance. The result of this study shows that organizational justice positively mediated the relationship between servant leadership and OCB. Donkor, Afriyie, AdjeiDanquah, and Nimsah (2015) reported interpersonal employee conflict as a mediator in the quantitative study. The result of the study shows that it mediates the relationship between leader characteristics and employee performance. The mediating effect of employee trust has been seen in previous research of Shahzad et al., (2013) in Pakistan. The result of this study showed that trust positively mediates the relationship of servant leadership and OCB. The other important organizational variable 'psychological ownership' was investigates as mediator between the relationships of dimensions of servant leadership with employee OCB performance (Bambale, 2014). The result of this study showed significant mediation between these two relationships. Chiniara \& Bentein (2016) proposed that servant leadership's emphasis on employee development improved task performance and OCB.

\section{HYPOTHESIS DEVELOPMENT AND RESEARCH FRAMEWORK}

On the basis of above literature, following hypothesis of the study is developed with the five sub hypothesis.

H: Interpersonal employee conflict negatively mediates the relationship between servant leadership and $O C B$

Ha: Interpersonal employee conflict mediates the relationship between Altruistic calling and academicians' OCB. 
$\mathrm{Hb}$ : Interpersonal employee conflict mediates the relationship between Emotional Healing and academicians' OCB.

Hc: Interpersonal employee conflict mediates the relationship between Wisdom and academicians' OCB.

Hd: Interpersonal employee conflict mediates the relationship between Persuasive Mapping and academicians' OCB.

He: Interpersonal employee conflict mediates the relationship between Organizational Stewardship and academicians' OCB.

Servant Leadership

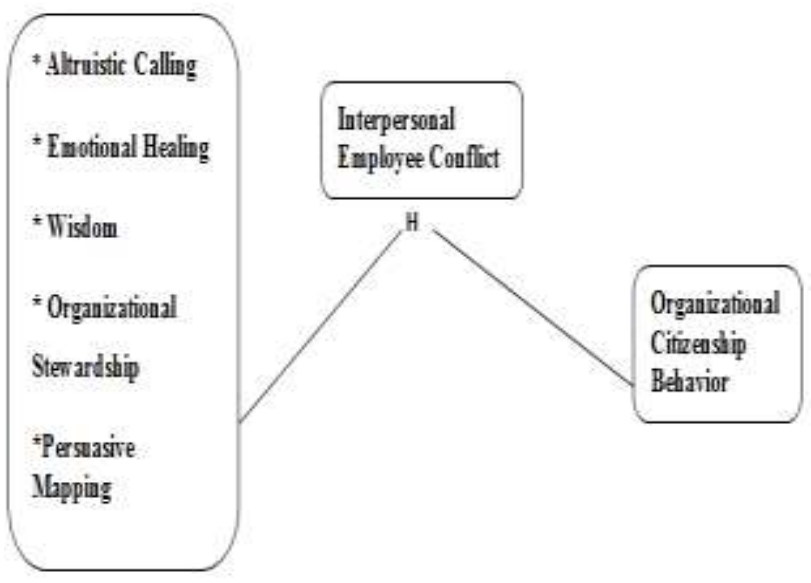

Figure 1. Research Framework of the study

\section{METHODOLOGY}

This quantitative empirical study was performed on the academicians' of the Malaysian Technical Universities Network (MTUN). Data was collected from the faculty members of the MTUN employees. Survey using google doc was distributed to the academicians (Professors, Associate Professors, Senior Lecturers, and Lecturers) of the four universities of this network. In total 750 forms were distributed using stratified proportionate sampling systematically to each $4^{\text {th }}$ academician. Total 390 forms were receive back as response rate was $52 \%$.

Appropriate statistics tests were employed to check the reliability and multicollinearity of data, using SPSS V25. Later, the SmartPLS was used to investigate validity of the model. Preacher \& Hayes (2008) approach was used to examine the mediating role of Interpersonal employee conflict between Servant leadership dimensions and the academicians OCB.

\section{ANALYSIS AND RESULTS}

Smart PLS was used to investigate the mediating role of Interpersonal employee conflict between the servant leadership and OCB. Bootstrapping was run, and indirect effect of Interpersonal employee conflict between servant leadership and OCB was examined. To start measurement model was run in PLS algorithm, which confirms the construct validities and discriminant validity of the construct as shown in the figure.

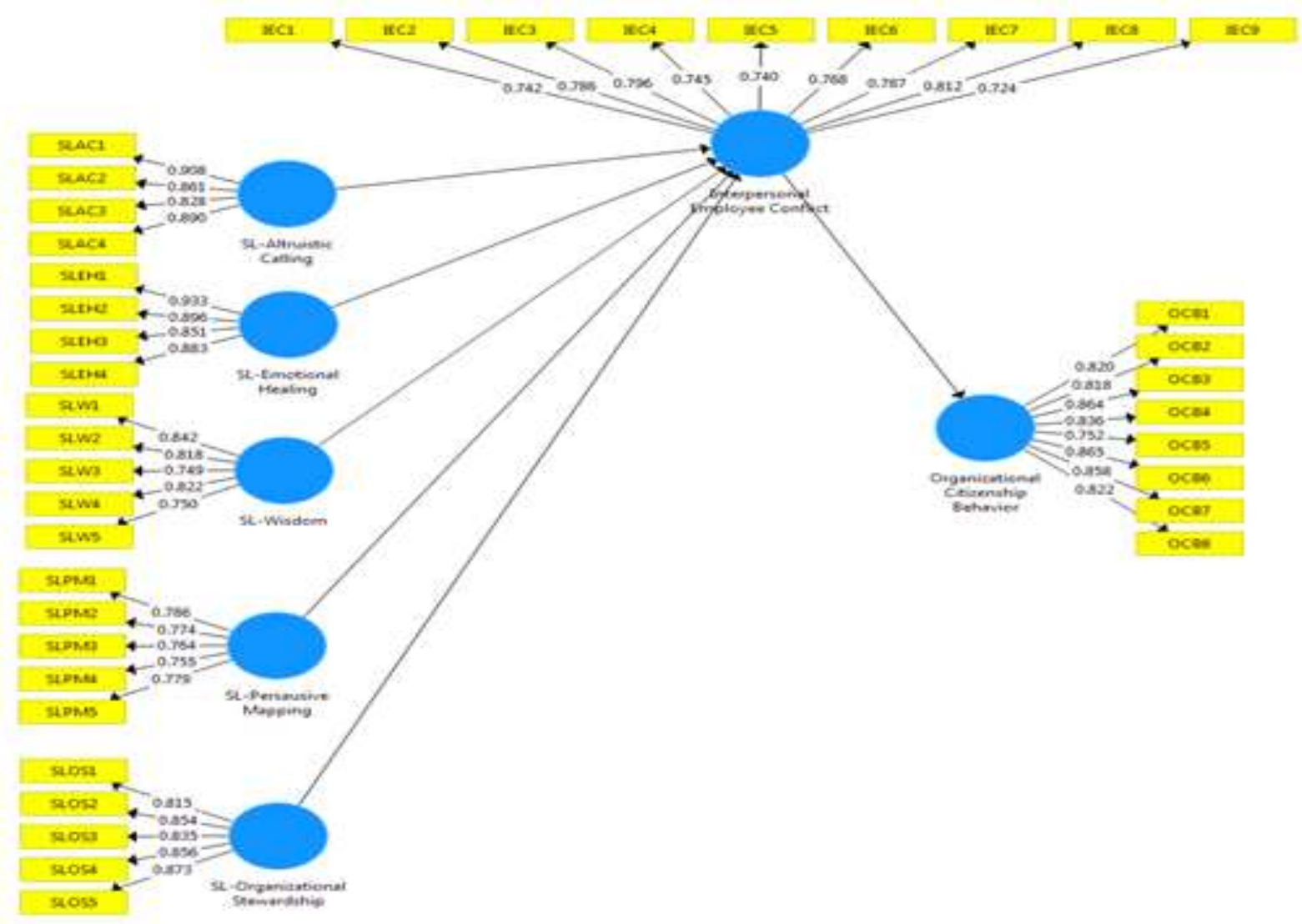


Data also has none of the multicollinearity issue and is reliable and validated.

\section{Indirect Effect or Mediation Effect of Servant Leadership on $O C B$}

In this study Interpersonal employee conflict was identified as a mediator between the relationship between servant leadership attributes such as Altruistic calling, Emotional healing, Wisdom, Persuasive mapping, and organizational stewardship with employee OCB. Therefore, five sub-hypotheses were formulated. Table 1 shows the result of mediation analysis. Hypothesis four of this study claims that Interpersonal employee conflict mediates the relationship between attributes of servant leadership and employee OCB. Further, this hypothesis was divided into five indirect paths. This study used (Preacher \& Hayes, 2008) method to test the mediation. This study claims that Interpersonal employee conflict mediates the relationship between attributes of servant leadership and employee OCB. Further, this hypothesis was divided into five indirect paths. This study used (Preacher \& Hayes, 2008) method to test the mediation. For this purpose, the current study used two-step approaches. At first step, all direct relationships were estimated in two ways, first direct relationships without a mediator and second direct relationship with mediators. At the second stage, all indirect effects have been calculated and their significance through the bootstrapping was calculated. At stage two of the analysis, mediator was estimated to calculate indirect effects. It was found that four indirect paths was significant and one was insignificant. The interpersonal employee conflict was not mediating the relationship between SL-persuasive mapping and OCB.

Figure 2 shows the mediation effect of interpersonal employee conflict in this study. This indicates the existence of mediation effect.

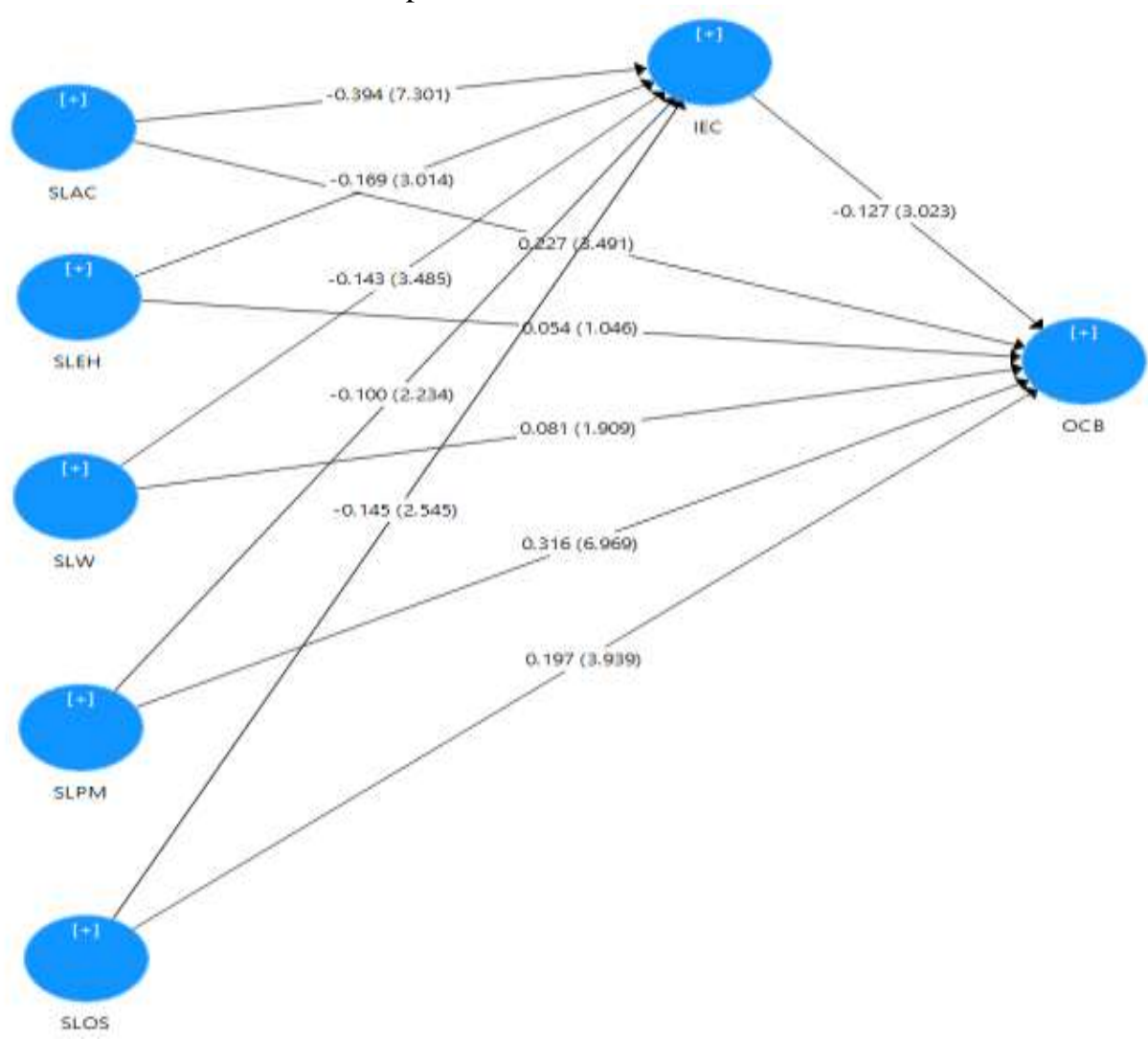

Ha: Interpersonal employee conflict mediates the relationship between SL attribute of Altruistic calling and

Hypothesis $\mathrm{H}$ stated that $\mathbf{H}$ : Interpersonal employee conflict significantly negatively mediates the relationship between attributes of servant leadership and OCB. This hypothesis was subdivided into five hypothesis that shows the indirect effect of interpersonal employee conflict on servant leadership attribute and OCB. The result shown in the table 1 that this four indirect hypothesis was supported, indicate the existence of mediating effect of interpersonal employee conflict between the relationship of servant leadership attributes such as Altruistic calling, emotional healing, wisdom, and organizational stewardship with OCB. The only indirect path of interpersonal employee conflict was not significantly mediates with SL-persuasive mapping and employee OCB. employee OCB. The results indicated that the path coefficient of the indirect path for mediation effect of Interpersonal Employee Conflict in the relationship between Altruistic calling and employee OCB was reported as 0.050 . To test the significance, bootstrapping procedure was adapted with 5000 irritations. T-value for the indirect path Altruistic calling $\rightarrow$ Interpersonal employee conflict $\rightarrow$ OCB was 3.819. This value is higher than 1.96 at two-tailed and p-value was 0.000 . This indicates the significance of the mediation effect. Also, confidence interval does not contain 
any 0.00 value thus, hypothesis H4a was supported.

Hb: Interpersonal employee conflict mediates the relationship between SL attribute of Emotional healing and employee OCB. The results indicated that the path coefficient of the indirect path for mediation effect of Interpersonal employee conflict in the relationship between Emotional healing and OCB was reported as 0.021. The Results indicates that the path coefficient of indirect path Emotional healing $\rightarrow$ Interpersonal employee conflict $\rightarrow$ Employee OCB was reported as 0.021 with $\mathrm{T}$ value 2.467 , this value was higher than 1.96 and p-value 0.017 . This indicates the significance of the mediation effect. Also, confidence interval does not contain any 0.000 value thus, hypothesis H4b was supported.

Hc: Interpersonal employee conflict mediates the relationship between SL attribute of Wisdom and employee OCB. Results indicated that the path coefficient of indirect path Wisdom $\rightarrow$ Interpersonal employee conflict $\rightarrow$ OCB was reported as 0.018. To test the significance, bootstrapping procedure was adapted with 5000 irritations. T-value for the indirect path Wisdom $\rightarrow$ Interpersonal employee conflict $\rightarrow$ OCB was 3.158, this value is higher than 1.96 and p-value was 0.002 indicating the significance of the mediation effect. Also, confidence interval does not contain any 0.00 value, thus hypothesis $\mathrm{H} 4 \mathrm{c}$ was supported.

Hd: Interpersonal employee conflict mediates the relationship between SL attribute of Persuasive mapping and employee OCB. Results indicated that the path coefficient of indirect path Persuasive mapping $\rightarrow$ Interpersonal employee conflict $\rightarrow$ OCB was reported as 0.013 . To test the significance, bootstrapping procedure was adapted with 5000 irritations. $\mathrm{T}$ value for the indirect path Persuasive mapping $\rightarrow$ Interpersonal employee conflict $\rightarrow$ OCB was 1.214, that was less than t-value 1.96 for mediation and $\mathrm{p}$ value was 0.091 . Thus hypothesis H4d was not supported.

He: Interpersonal employee conflict mediates the relationship between SL attribute of Organizational stewardship and employee OCB. Results indicated that the path coefficient of indirect path Organizational stewardship $\rightarrow$ Interpersonal employee conflict $\rightarrow$ OCB was reported as 0.018 . To test the significance, bootstrapping procedure was adapted with 5000 irritations. T value for the indirect path Organizational stewardship $\rightarrow$ Interpersonal employee conflict $\rightarrow$ OCB was 2.180, this value was higher than 1.96 and $\mathrm{p}$-value was 0.030 indicating the significance of the mediation effect. Also, confidence interval does not contain any 0.00 value, thus hypothesis $\mathrm{H} 4 \mathrm{e}$ was supported.

Table : The Results of structural model (Mediation effect)

Confidence Interval

\begin{tabular}{|c|c|c|c|c|c|c|c|c|}
\hline $\begin{array}{l}\text { Hypot } \\
\text { hesis }\end{array}$ & Paths & $\begin{array}{l}\text { Path } \\
\text { Coeffi } \\
\text { cient }\end{array}$ & S.E & t-value & P Values & $2.5 \% \mathrm{LL}$ & $\begin{array}{l}97.5 \\
\% \mathrm{UL}\end{array}$ & Results \\
\hline H4a & $\begin{array}{l}\text { Altruistic calling } \\
\rightarrow \text { Interpersonal employee } \\
\text { conflict } \rightarrow \text { OCB }\end{array}$ & 0.050 & 0.018 & 3.819 & 0.000 & 0.021 & 0.079 & Supported \\
\hline H4b & $\begin{array}{l}\text { Emotional healing } \rightarrow \\
\text { Interpersonal employee } \\
\text { conflict } \rightarrow \text { OCB }\end{array}$ & 0.021 & 0.010 & 2.467 & 0.017 & 0.006 & 0.039 & Supported \\
\hline $\mathrm{H} 4 \mathrm{c}$ & $\begin{array}{l}\text { Wisdom } \rightarrow \text { Interpersonal } \\
\text { employee conflict } \rightarrow \text { OCB }\end{array}$ & 0.018 & 0.008 & 3.158 & 0.002 & 0.006 & 0.033 & Supported \\
\hline H4d & $\begin{array}{l}\text { Persuasive mapping } \rightarrow \\
\text { Interpersonal employee } \\
\text { conflict } \rightarrow \text { OCB }\end{array}$ & 0.013 & 0.007 & 1.214 & 0.091 & -0.002 & 0.026 & $\begin{array}{c}\text { not } \\
\text { Supported }\end{array}$ \\
\hline H4e & $\begin{array}{l}\text { Organizational Stewardship } \\
\rightarrow \text { Interpersonal employee } \\
\text { conflict } \rightarrow \text { OCB }\end{array}$ & 0.018 & 0.010 & 2.180 & 0.030 & 0.004 & 0.036 & Supported \\
\hline
\end{tabular}

$\mathrm{S} . \mathrm{E}=$ Standard Error, $\mathrm{T}$ Value $=\mathrm{t}$ statistic value, $\mathrm{P}$ value $=$ Probability value

This results help us to understand that interpersonal employee conflict impacts the relationship of the four of the five constructs of servant leadership with academicians OCB. This help us to understand the importance of Interpersonal employee conflict.

\section{CONCLUSION}

This result leads us toward the understanding that servant leadership has indirect effect on the organizational citizenship behavior of academicians through interpersonal conflict, though this relationship is still significant in the most of the cases. Work stress is a reality in the organizations and conflict is a by product of the workstress which does appear in the interpersonal employee conflict. It is responsibility of leadership to exert behaviours which in the longer run, support employees and reduce their interpersonal bad feelings so the OCB is not affected. So orhanizations can survive and thrive. As academicians are the most important elements of the society. 


\section{ACKNOWLEDGEMENT}

"This paper is sponsored by the Research Management Center (RMC) of Universiti Tun Hussein Onn Malaysia (UTHM), Johor Malaysia"

\section{REFERENCE}

1. Newman, M., \& Smith, K. H. (2014). Emotional Intelligence and Emotional Labour: A Comparison Study Using the Emotional Capital Report (ECR). Education and Society, 32(1), 41-62.

2. Ng, S. M., Ke, G. N., \& Raymond, W. (2014). The mediating role of work locus of control on the relationship among emotional intelligence, organisational citizenship behaviours, and mental health among nurses. Australian Journal of Psychology, 66(4), 207-215.

3. Ngah, R., Jusoff, K., \& Rahman, Z. A. (2009). Emotional Intelligence of Malaysian Academia towards Work Performance. International Education Studies, 2(2), 103112.

4. Northouse, P. G. (2007). Leadership: Theories and practices: Thousand Oaks: Sage Publishing.

5. Northouse, P. G. (2018). Leadership: Theory and practice: Sage publications.

6. Schreuder, J. A., Roelen, C. A., Van Zweeden, N. F., Jongsma, D., Van der Klink, J. J., \& Groothoff, J. W. (2011). Leadership effectiveness and recorded sickness absence among nursing staff: a cross-sectional pilot study. Journal of Nursing Management, 19(5), 585-595.

7. Organ, D. (2006). Treating employees fairly and OCB: sorting the effect of job satisfaction, organizational commitment and procedural justice: Plenum Publishing Corporation: USA.

8. Pallant, J. (2010). SPSS survival manual: A step by step guide to data analysis using SPSS . Maidenhead: Open University Press/McGraw-Hill.

9. Panaccio, A., Henderson, D. J., Liden, R. C., Wayne, S. J., \& Cao, X. (2015). Toward an understanding of when and why servant leadership accounts for employee extrarole behaviors. Journal of business and psychology, 30(4), 657-675.

10. Panteli, N., \& Sockalingam, S. (2005). Trust and conflict within virtual inter-organizational alliances: a framework for facilitating knowledge sharing. Decision support systems, 39(4), 599-617.

11. Qadri, U. A., Hassan, S. S., \& Sheikh, M. A. (2017). The Mediating Role of Internal Locus of Control and Job Stress between Spiritual Intelligence and Job Performance. Pakistan Journal of Commerce \& Social Sciences, 11(2)

12. Ramachandran, Y., Jordan, P. J., Troth, A. C., \& Lawrence, S. A. (2011). Emotional intelligence, emotional labour and organisational citizenship behaviour in service environments. International Journal of Work Organisation and Emotion, 4(2), 136-157.

13. Ramli, A., \& Desa, N. M. (2014). The relationship between servant leadership and organizational commitment: The Malaysian perspectives. International Journal of Management and Sustainability, 3(2), 111123.

14. Reb, J., Narayanan, J., Chaturvedi, S., \& Ekkirala, S. (2017). The mediating role of emotional exhaustion in the relationship of mindfulness with turnover intentions and job performance. Mindfulness, 8(3), 707-716.

15. Robbins, S., Judge, T., \& Sobral, F. (2010). Comportamento organizacional: teoria e prática no contexto brasileiro: Pearson Prentice Hall.

16. Sanchez-Burks, J., Neuman, E. J., Ybarra, O., Kopelman, S., Park, H., \& Goh, K. (2008). Folk wisdom about the effects of relationship conflict. Negotiation and Conflict Management Research, 1(1), 53-76.

17. Yukl, G., \& Michel, J. W. (2006). Proactive influence tactics and leader member exchange. Power and influence in organizations, 87-103.

18. Zehir, C., Akyuz, B., Eren, M. S., \& Turhan, G. (2013). The indirect effects of servant leadership behavior on organizational citizenship behavior and job performance: Organizational justice as a mediator. International Journal of Research in Business and Social Science, 2(3), 1. 